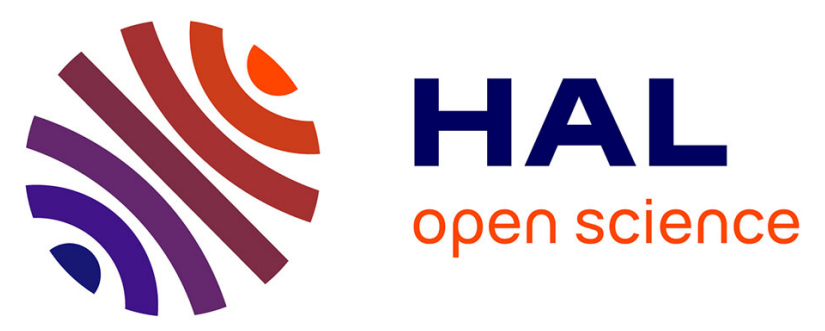

\title{
Building of an Electrical Machine Thermal Model in the Context of a Hybrid Electric Vehicle Global Optimization.
}

Mathias Le Guyadec, Emmanuel Vinot, Laurent Gerbaud, Patrick Lombard, Agnès Chaumond, Thomas Boussey

\section{To cite this version:}

Mathias Le Guyadec, Emmanuel Vinot, Laurent Gerbaud, Patrick Lombard, Agnès Chaumond, et al.. Building of an Electrical Machine Thermal Model in the Context of a Hybrid Electric Vehicle Global Optimization.. VPPC, Dec 2017, Belfort, France. hal-01713398

\section{HAL Id: hal-01713398 https://hal.science/hal-01713398}

Submitted on 22 Feb 2018

HAL is a multi-disciplinary open access archive for the deposit and dissemination of scientific research documents, whether they are published or not. The documents may come from teaching and research institutions in France or abroad, or from public or private research centers.
L'archive ouverte pluridisciplinaire HAL, est destinée au dépôt et à la diffusion de documents scientifiques de niveau recherche, publiés ou non, émanant des établissements d'enseignement et de recherche français ou étrangers, des laboratoires publics ou privés. 


\title{
Building of an Electrical Machine Thermal Model in the Context of a Hybrid Electric Vehicle Global Optimization.
}

\author{
Mathias Le Guyadec*†, Emmanuel Vinot*, Laurent Gerbaud ${ }^{\dagger}$, \\ Patrick Lombard ${ }^{\ddagger}$, Agnès Chaumond $^{*}$ and Thomas Boussey ${ }^{\dagger}$ \\ *Univ Lyon, IFSTTAR, AME, LTE 69500 Bron, France \\ Email: mathias.le-guyadec@ifsttar.fr \\ Telephone: (+33)4 78656857 \\ ${ }^{\dagger}$ Univ. Grenoble Alpes, CNRS Grenoble INP, G2Elab, F-38000 Grenoble, France \\ $\ddagger$ Altair-France, 38340 Meylan, France
}

\begin{abstract}
The understanding of the thermal phenomena in an Electrical Machine is significant because it influences the performances of the machine and its lifetime. In the context of Hybrid Electric Vehicles (HEV) sizing, it also impacts the performances of the entire vehicle. The paper describes the building of a robust thermal circuit model dedicated to watercooled electrical machines as those used in HEV. A finite element analysis is used to set the thermal parameters of a lumped parameter network. The sensitivity of the thermal parameters is analysed.

Keywords-Hybrid Electric Vehicle, Interior Permanent Magnet Synchronous Machine, thermal model, sensitivity analysis.
\end{abstract}

\section{INTRODUCTION}

Nowadays, transportation is one of the main sources of greenhouse gas emissions [1] and pollutants. Hybrid electric vehicles (HEV) are a serious alternative to reduce the emissions of the conventional vehicles. Energy recovery at braking can indeed save up to $30 \%$ fuel on an urban drive.

However, HEV are complex systems because the component sizing, the energy management and the driving cycle are strongly linked [2]. For instance it is difficult to size the electrical machine (EM) separately because its own operating cycle depends on the other component sizing and on the energy management. The EM operating cycle has to be predetermined from the vehicle cycle with considerations on the management of the system. Besides, the characteristics of the components may influence the energy management. For example it can be adapted to the best efficiency area of the EM.

The approach used in the paper considers the entire system with these interactions. As shown in Fig. 1, the paper focuses on the parallel hybrid architecture of HEV. A global optimization process [3] is used to minimize the fuel consumption of the vehicle over a driving cycle. A specific electromagnetic model of the EM is used to size precisely the machine.

The study of the EM in an HEV context is very particular. Indeed the volume of the EM is constrained, and it has often to be cooled by external and internal ways.

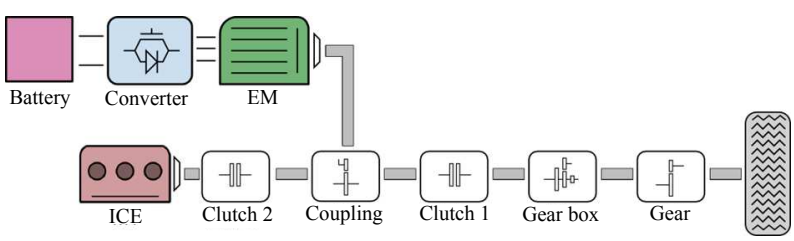

Fig. 1. Hybrid parallel architecture.

The EM is a main component of the architecture, and its thermal behaviour influences its lifetime, its efficiency, its performances (e.g. the maximal torque) and consequently the performances of the entire vehicle.

A better understanding of the thermal exchanges in the machine will ensure better performances. Indeed, the overheating of the copper insulation is the main cause of EM failures [4]. So, the knowledge of the temperature in critical areas such as the windings and the magnets is important to manage the sizing.

The paper focuses on the development of a thermal model of the EM. First, the thermal analysis problem is introduced. Then, a 3D finite element model is chosen as a reference to build a fast and accurate lumped parameter network. A particular attention is paid to the exchanges around the endwindings. A first sensitivity analysis of the model and its integration in the global optimization process of the HEV are finally introduced.

\section{ELECTRICAL MACHINE THERMAL MODELLING}

\section{A. Presentation of the electrical machine}

The studied EM is a permanent magnet synchronous machine [5], which is commonly used in HEV. Its cooling is ensured by:

- an adjustable water/glycol flow through the casing;

- an internal cooling oil, which is splattered on the endwindings area.

Copper losses and stator iron losses are the main heat sources in the EM. Rotor losses are much lower and are 
subsequently neglected. The heat is dissipated through the machine by different ways:

- conduction;

- convection;

- radiation.

Radiations are neglected as the EM has a forced cooling system [6].

The thermal model built in Section III is based on the geometry of a reference EM which is studied in [7]. Useful data on its thermal behaviour are available in [5].

\section{B. Difficult aspects of electrical machine thermal analysis}

The thermal study of EM is quite difficult because the thermal exchanges are linked to:

- the EM geometry;

- the multiplicity of the used materials;

- the manufacturing process (e.g. contact between materials).

As heat is dissipated in $3 \mathrm{D}$, the modelling is more difficult. The exchanges through the massive materials are quite easy to understand, but other areas are much more complex [6][8][9]:

- the interface gaps between materials and cooling (e.g. between the end-windings and the cooling oil);

- the interface gaps between materials;

- non-homogeneous areas like windings;

- the air gap.

Measurement on the EM are often the best solution to assign the thermal parameters representing these complex areas: equivalent conduction coefficients, heat-transfer coefficients, etc. However they are not always feasible. Hence, this work is based on the results of [5] and the presented numerical model.

The paper aims to present a robust thermal model, computing temperatures on critical areas such as the windings. The model has to depend on the geometry of the EM, and to be fast enough to be used during an optimization process. An overview of the modelling approaches is following.

\section{State of the art of electrical machine thermal modelling}

There are two main modelling approaches for the thermal behaviour of the EM:

- Lumped parameter thermal networks (LPTN): Thermal exchanges are represented by an equivalent thermalelectrical circuit. Therefore, the calculation of the temperatures is really fast. However, a strong knowledge of the thermal paths through the machine is necessary to build a precise equivalent circuit;

- Numerical approaches: These methods compute local phenomena as the temperature gradient. However, the solving is time-consuming. Two kinds of tools exist:

- Finite element analysis (FEA): it is well adapted to the calculation into solid areas of the machine (conduction). The most important limitation is the definition of the convection boundaries. Flux [10] is a software using such an approach;
- Computational fluid dynamics (CFD): it is mainly used for calculation into fluid areas such as end spaces (convection). Heat transfer coefficients can be approximated thanks to such an approach. An example is presented in [11].

Advantages and drawbacks of each approach are summarized in Table I. LPTN is the fastest solution but is highly de-

TABLE I

COMPARISON OF THE DIFFERENT THERMAL APPROACHES

\begin{tabular}{|c|c|c|c|}
\hline & LPTN & FEA & CFD \\
\hline speciality & & conduction & convection \\
\hline accuracy & - & + & ++ \\
\hline calculation duration & $<$ second & minutes & hours \\
\hline model setup & short & long & long \\
\hline
\end{tabular}

pendent on the thermal parameters. FEA is very efficient for the conduction modelling, in particular in non-homogeneous areas, but depends on the same critical parameters as LPTN. Finally, CFD is the most effective approach for the convection modelling in complex areas but at a very high setup and computation cost.

It is obvious that FEA and CFD are not adapted to be used during an optimization process which is already timeconsuming. However, these fine models are appropriated during pre- and post-processing. For instance, FEA can be used to understand the thermal exchanges and to build a robust LPTN.

\section{BUILDING OF A ROBUST THERMAL MODEL}

This section describes the process to build a parametrized thermal model that is used during the HEV global optimization. A 3D finite element model is built to understand the phenomena in the machine. Then, a faster LPTN is adapted to fit the $3 \mathrm{D}$ results. The model has to be robust regarding the geometrical and the thermal parameters. In this way, a smart design of the network and a sensitivity analysis on the critical thermal coefficients have to be considered.

\section{A. Approach and hypothesis}

A steady state approach is chosen. In fact, if the maximal temperature constraint is respected at steady state for a given machine control, it will also be respected during a transient operation of the driving cycle, for the same control. Table II presents the maximum permissible temperatures for the critical areas in the machine. These constraints were collected from [5]. The VACODYM 688 TP [12] was chosen as a reference permanent magnet.

FEA suits well to understand the conduction phenomena in the EM. However, the main difficulties are still the cooling exchanges which are located around the end-windings. The challenge is to represent these complex exchanges using finite elements.

Flux 3D allows to represent convection only as a boundary condition. For internal exchanges (cooling oil), an equivalent conduction representation is used to describe the end space 
TABLE II

THERMAL CONSTRAINTS IN THE EM

\begin{tabular}{|c|c|}
\hline Area & Maximum temperature $\left[{ }^{\circ} \mathbf{C}\right]$ \\
\hline winding & 170 \\
\hline cooling oil & 158 \\
\hline permanent magnet & 220 \\
\hline
\end{tabular}

convection phenomena. It is composed of a thin layer with an equivalent conductivity $\lambda_{e q}$ at the interface, and a high conductivity area in the cavity space $\left(\lambda_{\text {oil }}\right)$. The two parameters are chosen according (1) and (2).

$$
\begin{gathered}
\lambda_{e q}=h \times E_{e q} \\
\lambda_{\text {oil }}=1000 \mathrm{~W} \cdot \mathrm{m}^{-1} \cdot{ }^{\circ} \mathrm{C}^{-1}
\end{gathered}
$$

$h$ is the heat transfer coefficient between the end-winding and the cooling oil and $E_{e q}$ the thickness of the thin layer. The value of $\lambda_{\text {oil }}$ is arbitrary chosen to represent the thermal homogeneity of the cooling oil, due to its continuous motion. This equivalent representation was validated in Flux 3D by comparisons with a model considering the end-winding cooled by convection (boundary condition). Similar results on the heat paths and the temperatures were found.

\section{B. Building of the finite element model and analysis}

The software tool Flux [10] is used to build the finite element model. The steady state thermal application is used to understand the thermal exchanges. A view of the geometry (without the casing) is presented by Fig. 2. End windings are represented by a massive volume (in yellow on Fig. 2). The

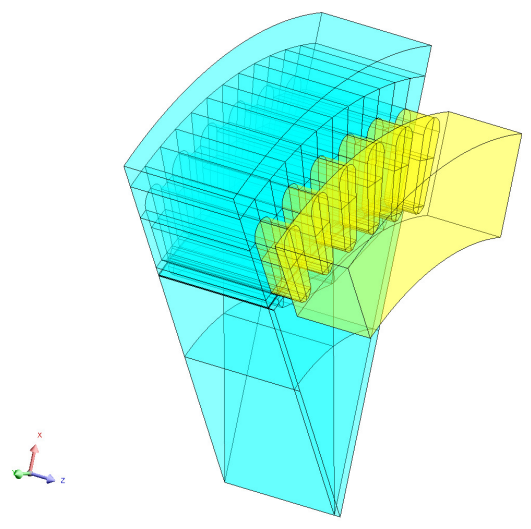

Fig. 2. EM geometry used for the FEA (Flux).

main data concerning the building of the model are presented in Table III.

The losses injected in the machine are also presented in Table III. Copper and iron losses are deduced thanks to the magnetic circuit model of the EM which is presented in [3]. These values are obtained at a reference working point : 180 $N \cdot m @ 960 \mathrm{rpm}$ which is similar to that used in [5].
TABLE III

CHARACTERISTICS OF THE FINITE ELEMENT MODEL

\begin{tabular}{|c|c|c|}
\hline & Characteristics & Ref. \\
\hline \hline Volumes & $\lambda:\left[W \cdot m^{-1} \cdot{ }^{\circ} \mathrm{C}^{-1}\right]$ & \\
\hline permanent magnets & $\lambda_{P M}=47.3$ & {$[5]$} \\
\hline casing & aluminium / $\lambda_{\text {cas }}=52$ & \\
\hline slot (axial) & copper $/ \lambda_{\text {slax }}=394$ & \\
\hline slot (radial) & copper \& insulation $/ \lambda_{\text {slrad }}=4.7$ & {$[13]$} \\
\hline end-winding & copper \& insulation $/ \lambda_{\text {end }}=4.7$ & \\
\hline air gap & oil/air $/$ Couette flow / $\lambda_{\text {gap }}=10$ & {$[5]$} \\
\hline stator \& rotor (axial) & iron $/ \lambda_{a x}=5.21$ & {$[5]$} \\
\hline stator \& rotor (radial) & iron $/ \lambda_{\text {rad }}=51.9$ & {$[5]$} \\
\hline \hline Surfaces & $h:\left[W \cdot m^{-2} \cdot{ }^{\circ} \mathrm{C}^{-1}\right] \& E:[m]$ & \\
\hline stator/casing contact & $\lambda_{c t c}=0.075 / E_{c t c}=6.10^{-5}$ & {$[5][8]$} \\
\hline oil equivalent layer & $\lambda_{e q}=0.0125 / E_{\text {eq }}=5.10^{-4}$ & \\
& $\Longleftrightarrow h_{\text {oil }}=25$ & {$[5]$} \\
\hline slot insulation & Mylar-type material & \\
& $\lambda_{\text {slins }}=0.125 / E_{\text {slins }}=19.10^{-5}$ & {$[5][14]$} \\
\hline casing forced cooling & $T_{\text {cas }}=97^{\circ} \mathrm{C}$ & {$[5]$} \\
\hline casing natural cooling & $T_{\infty}=50^{\circ} \mathrm{C} / h_{\text {cas }}=5$ & \\
\hline \hline Losses & $P:[W]$ & \\
\hline copper losses & $P_{I R}=84$ & \\
\hline iron losses (stator) & & \\
\hline
\end{tabular}

Thermal results are shown in Fig. 3. The maximum temperature is about $149{ }^{\circ} \mathrm{C}$ and is obtained at the end of the endwinding. Fig. 5 shows complementary results. But the main result is the understanding of the thermal exchange paths:

- the main path is from the end-windings to the slot and then to the casing. About $92 \%$ of the generated heat is removed through the stator/casing interface;

- the cooling oil in the cavity helps to limit the endwindings temperature, but there is no main exchange through the interface;

- the rotor has a minor impact on the heat transfer.

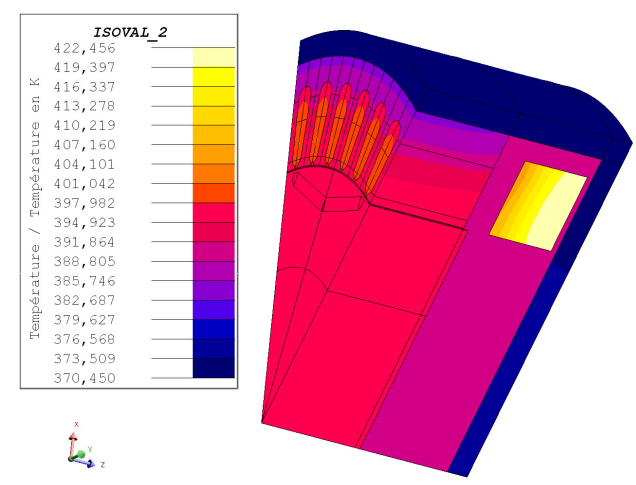

Fig. 3. EM temperatures obtained (Flux). 


\section{Building of the LPTN and results}

The LPTN is developed in Matlab and is schematically presented by Fig. 4. The results from FEA are used to represent the heat paths with the best accuracy. The model operates as follows:

- losses and geometrical parameters are inputs;

- thermal coefficient and thermal resistances are defined from the literature or the FEA;

- temperatures on the nodes of the network are outputs.

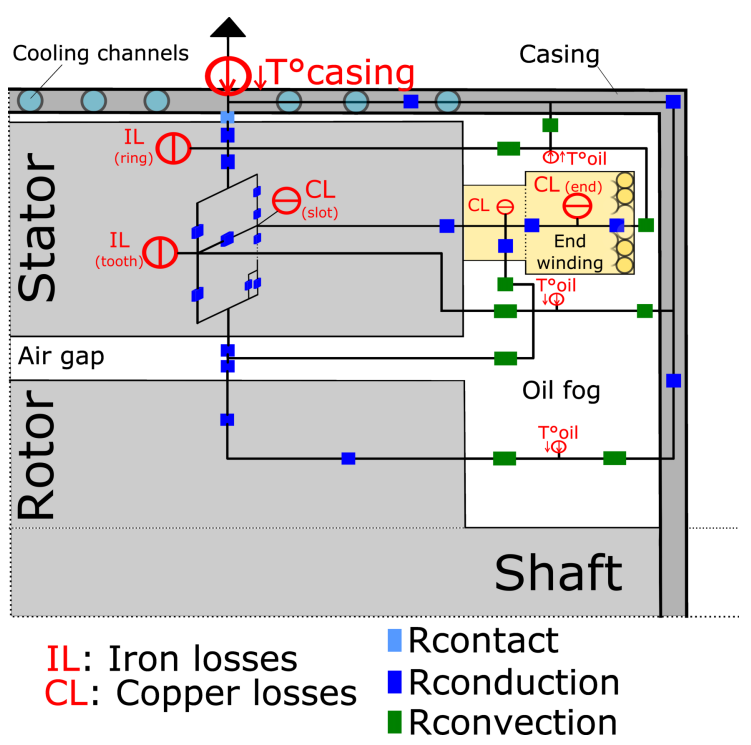

Fig. 4. Thermal network considered

Fig. 4 is a representation of the axial section of the EM. The sizes are not strictly respected. The casing is cooled thanks to water channels whose temperature is externally regulated. The copper losses (CL) and the iron losses (IL) generate heat into the machine. The heat paths are represented by equivalent thermal resistances:

- in dark blue for conduction;

- in light blue for contact;

- in green for convection.

Note that oblique lines represent orthoradial heat exchanges in the stator (between tooth and slot as instance). The internal cooling is ensured by an oil/air mixture (oil fog) which is splattered on the end-windings (yellow).

LPTN is an analogy between thermal and electrical phenomena. As instance, the temperature $\left[{ }^{\circ} \mathrm{C}\right]$ is equivalent to the voltage $[V]$ and heat flow $[W]$ is equivalent to the current $[A]$. Thermal resistances depends on the thermal mode considered and the sizes of the exchange area. The following equations are used to compute the thermal resistances of the model, where $E, \lambda$ and $h$ remains as defined previously on Section III:

- conduction mode through a parallelepiped, with a section $\mathrm{S}\left[m^{2}\right]$;

$$
R_{c d, p l p}=\frac{E}{\lambda \times S}
$$

- conduction mode through a cylinder (radial), with an external radius $R_{e x t}$, an internal radius $R_{i n t}[\mathrm{~m}]$ and an angle $\alpha[\mathrm{rad}]$;

$$
R_{c d, c y l}=\frac{\ln \left(\frac{R_{e x t}}{R_{\text {int }}}\right)}{\alpha \times E \times \lambda}
$$

- convection mode on a surface $\mathbf{S}\left[\mathrm{m}^{2}\right]$;

$$
R_{c v}=\frac{1}{h \times S}
$$

An analytical calculation is performed to find the temperature at each node. In fact, it consists on solving the system of linear equations deduced from the Kirchoff's law applied at each circuit node.

The result is presented by Fig. 5. It shows the temperature profile inside the machine. The reference results obtained with FEA are represented in blue. Note that for each EM area, there is a range of temperature, except for the highest temperature in the EM located in the end-windings and represented by a cross. Red circles and cross are the temperatures find thanks to the LPTN.

The stator and the rotor temperatures fits the FEA mean results with an error lower than $3 \%$, as well as the oil temperature $\left(120^{\circ} \mathrm{C}\right)$ which is not represented. A comparison between FEA and the LPTN results on the thermal flow shows that the thermal paths are respected. The highest difference is found on the exchange between the slots and the stator with $10 \%$ of error. Additional work has to be carried out on the slot model to improve this result.

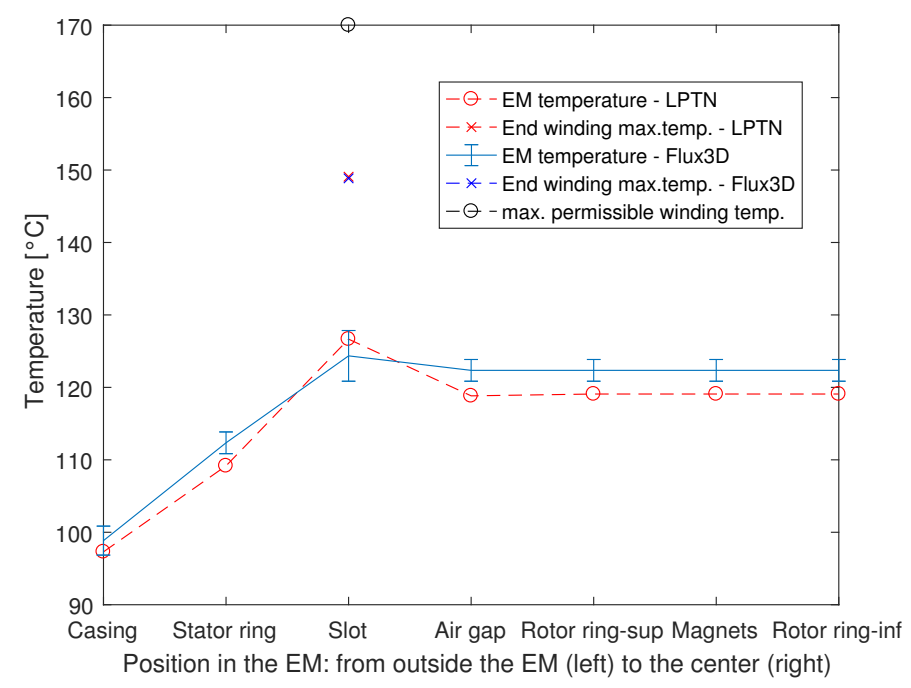

Fig. 5. EM temperature profile. FEA (blue) and LPTN (red) are compared.

\section{SENSITIVITY ANALYSIS}

A sensitivity analysis of the thermal network is used to check the robustness of the model. Indeed, as shown by first simulations, some thermal parameters seems to highly influence the outputs: 
- $h_{o i l}$, the heat transfer coefficient between the end-winding and the cooling oil;

- $\lambda_{c t c}$, the conduction coefficient of the contact between the stator and the casing;

- $\lambda_{\text {slins }}$, the conduction coefficient of the slot insulation.

As a first analysis, several simulations were performed on the finite element model. A design of experiments is built on three factors. Each factor can take several values:

- $h_{\text {oil }}: 25,50$ or $100 \mathrm{~W} \cdot \mathrm{m}^{-2} \cdot{ }^{\circ} \mathrm{C}^{-1}$;

- $E_{\text {ctc }}: 6.10^{-5}$ or $12.10^{-5} \mathrm{~m}$;

- $E_{\text {slins }}: 19.10^{-5}$ or $50.10^{-5} \mathrm{~m}$.

The design of experiments enables to study the effect of each factor and the interaction effect on the temperatures inside the machine.

Five temperatures are studied: $T_{\text {max }}, T_{\text {rotor }}, T_{\text {oil }}, T_{\text {tooth }}$ and $T_{\text {slot }}$. Note that $T_{\max }$ is always found in the end-windings. A statistical model is built for each of these temperature to determine if the factors are involved in their variations. Results are presented by Table IV.

TABLE IV

PROPORTION OF THE TEMPERATURE VARIATION CAUSED BY EACH FACTOR

\begin{tabular}{|c|c|c|c|c|c|}
\hline & $\boldsymbol{T}_{\boldsymbol{m a x}}$ & $\boldsymbol{T}_{\boldsymbol{r o t o r}}$ & $\boldsymbol{T}_{\text {oil }}$ & $\boldsymbol{T}_{\text {tooth }}$ & $\boldsymbol{T}_{\text {slot }}$ \\
\hline $\boldsymbol{h}_{\text {oil }}{ }^{1}$ & $\underline{59 \%}$ & $17 \%$ & $8 \%$ & $13 \%$ & $15 \%$ \\
\hline $\boldsymbol{E}_{\text {ctc }}{ }^{1}$ & $28 \%$ & $\underline{80 \%}$ & $\underline{82 \%}$ & $\underline{85 \%}$ & $\underline{51 \%}$ \\
\hline $\boldsymbol{E}_{\text {slins }}{ }^{1}$ & $10 \%$ & & $8 \%$ & & $32 \%$ \\
\hline \hline $\boldsymbol{h}_{\text {oil }} * \boldsymbol{E}_{\text {ctc }}{ }^{2}$ & & $\mathrm{~S}^{3}$ & $\mathrm{~S}$ & $\mathrm{~S}$ & $\mathrm{~S}$ \\
\hline $\boldsymbol{h}_{\text {oil }} * \boldsymbol{E}_{\text {slins }}{ }^{2}$ & & & & & $\mathrm{~S}$ \\
\hline
\end{tabular}

For each of the studied temperature, the generalized linear model explains more than $90 \%$ of its variability. Table IV shows that $E_{c t c}$ and $h_{\text {oil }}$ has to be chosen with precision because their variations are the main causes of the temperature variations. In particular, $h_{\text {oil }}$ explains $59 \%$ of the variations of $T_{\max }$, which is the main constraint during the optimization process.

Table $\mathrm{V}$ summarizes the maximum temperature variation observed for each factor and its considered range. The results

TABLE V

MAXIMUM TEMPERATURE VARIATION ON THE RANGE OF EACH FACTOR

\begin{tabular}{|c|c|c|c|c|c|}
\hline & $\boldsymbol{T}_{\boldsymbol{m a x}}$ & $\boldsymbol{T}_{\text {rotor }}$ & $\boldsymbol{T}_{\text {oil }}$ & $\boldsymbol{T}_{\text {tooth }}$ & $\boldsymbol{T}_{\text {slot }}$ \\
\hline $\boldsymbol{h}_{\text {oil }}$ & $\underline{-15^{\circ} \mathrm{C}}$ & $-5^{\circ} \mathrm{C}$ & $-2^{\circ} \mathrm{C}$ & $-4^{\circ} \mathrm{C}$ & $-6^{\circ} \mathrm{C}$ \\
\hline $\boldsymbol{E}_{\text {ctc }}$ & $+7^{\circ} \mathrm{C}$ & $+8^{\circ} \mathrm{C}$ & $+6^{\circ} \mathrm{C}$ & $+10^{\circ} \mathrm{C}$ & $+8^{\circ} \mathrm{C}$ \\
\hline $\boldsymbol{E}_{\text {slins }}$ & $+4^{\circ} \mathrm{C}$ & & $+2^{\circ} \mathrm{C}$ & & $+7^{\circ} \mathrm{C}$ \\
\hline \hline$h_{\text {oil }} * \boldsymbol{E}_{\text {ctc }}$ & & $\underline{-9^{\circ} \mathrm{C}}$ & $\underline{-10^{\circ} \mathrm{C}}$ & $\underline{-13^{\circ} \mathrm{C}}$ & $\underline{-15^{\circ} \mathrm{C}}$ \\
\hline$h_{\text {oil }} * \boldsymbol{E}_{\text {slins }}$ & & & & & $-12^{\circ} \mathrm{C}$ \\
\hline
\end{tabular}

show temperature variations up to $15^{\circ} \mathrm{C}$ in critical areas such

\footnotetext{
${ }^{1}$ Single effect only

${ }^{2}$ Interaction effect

${ }^{3}$ Significant effect
}

as the copper windings. It confirms that the choice of those parameters is a significant work to get a good precision on the resulting temperatures. This work will be carried on with:

- the addition of a lower value of $E_{c t c}$, to check the linearity of its effect;

- the variation of $\lambda_{\text {end }}$, the conduction coefficient in the end-windings, which is in fact anisotropic.

\section{PERSPECTIVES}

A variance-based sensitivity analysis is selected to complete the previous work. The Sobol indices [15] will be used to find out the influence of every parameter on the temperatures of the LPTN. Nevertheless, this work may only begin after the finalisation of the thermal circuit modelling.

Final work will be to include the thermal constraint into the global optimization process [3] of the HEV. During the EM operating, the temperatures inside the EM may not exceed those presented in Table II. The thermal model will be used during the building of the efficiency map of the EM. Operating points which lead to an exceed of the maximal temperatures will not be used by the energy management process.

Finally, results will be analysed to understand the influence of the thermal constraint on the design and the energy management of the HEV.

\section{CONCLUSION}

In the paper, the building of a thermal model of an EM based on a circuit equivalent approach is presented. The difficulties of such a model are explained. The chosen approach includes the building of a reference FEA to understand the heat paths in the machine. A fast thermal equivalent circuit is also built to be used during the global optimization process of an HEV. First results show that the LPTN fit the temperatures found by the FEA with less than $3 \%$ of error. A first analysis on the finite element model shows that an uncertainty on several thermal parameters $\left(h_{o i l}\right.$ and $E_{c t c}$ ) leads to important differences on the temperatures (up to $15^{\circ} \mathrm{C}$ ) in critical areas of the machine. A variance-based sensitivity analysis is intended to check the robustness of the LPTN. The integration of the thermal constraint into the global optimization process of the HEV will conclude this work.

\section{ACKNOWLEDGMENT}

The authors would like to thank the ALTAIR society for the free use of the finite element program FLUX.

\section{REFERENCES}

[1] n. W. Eurostat, "Greenhouse gas emission statistics.." http://ec.europa.eu/eurostat/statistics-explained/index.php/Greenhouse_ gas_emission_statistics, Nov. 2016.

[2] E. Silvas, E. Bergshoeff, T. Hofman, and M. Steinbuch, "Comparison of bi-level optimization frameworks for sizing and control of a hybrid electric vehicle," in Vehicle Power and Propulsion Conference (VPPC), 2014 IEEE, pp. 1-6, Oct 2014.

[3] V. Reinbold, E. Vinot, L. Garbuio, and L. Gerbaud, "Optimal sizing of an electrical machine using a magnetic circuit model: application to a hybrid electrical vehicle," IET Electrical Systems in Transportation, vol. 6 , no. 1 , pp. 27-33, 2016. 
[4] M. L. Idoughi, Extraction de modèles thermiques simplifiés des machines électriques à partir d'un calcul du champ de températures. $\mathrm{PhD}$ thesis, Université Paris Sud-Paris XI, 2011.

[5] J. Hsu, "Report on toyota prius motor thermal management," tech. rep., ORNL, 2005.

[6] B. Assaad, Contribution à la prise en compte des aspects thermiques des machines électriques dans un environnement mécatronique. $\mathrm{PhD}$ thesis, Compiègne, 2015.

[7] J. Hsu, C. Ayers, and C. Coomer, "Report on toyota/prius motor design and manufacturing assessment," Federal Register, pp. 1-15, 2004.

[8] D. Staton, A. Boglietti, and A. Cavagnino, "Solving the more difficult aspects of electric motor thermal analysis in small and medium size industrial induction motors," IEEE Transactions on Energy Conversion, vol. 20, no. 3, pp. 620-628, 2005.

[9] A. Boglietti, A. Cavagnino, and D. Staton, "Determination of critical parameters in electrical machine thermal models," IEEE Transactions on Industry Applications, vol. 44, no. 4, pp. 1150-1159, 2008.

[10] Altair, "Altair flux." http://www.altairhyperworks.com/product/flux, Sept. 2017.

[11] C. Jungreuthmayer, T. Bauml, O. Winter, M. Ganchev, H. Kapeller, A. Haumer, and C. Kral, "A detailed heat and fluid flow analysis of an internal permanent magnet synchronous machine by means of computational fluid dynamics," IEEE Transactions on Industrial Electronics, vol. 59, no. 12, pp. 4568-4578, 2012.

[12] V. Co., "Rare earth permanent magnets vacodym \& vacomax." http://www.vacuumschmelze.com/fileadmin/Medienbiliothek_2010/ Downloads/DM/VACODYM-VACOMAX-PD002_2015_en.pdf, 2015.

[13] J. Lutun, Modélisation thermique des alternateurs automobiles. $\mathrm{PhD}$ thesis, Université de Grenoble, 2012.

[14] R. Balke and D. Cipriani, "Channel, shaped, laminated, high temperature slot wedge for dynamoelectric machines," May 22 1973. US Patent $3,735,169$.

[15] A. Saltelli, P. Annoni, I. Azzini, F. Campolongo, M. Ratto, and S. Tarantola, "Variance based sensitivity analysis of model output. design and estimator for the total sensitivity index," Computer Physics Communications, vol. 181, no. 2, pp. 259-270, 2010. 